\title{
Low rate of reoperations after acute type A aortic dissection repair from The Nordic Consortium Registry
}

Emily Pan, BM, ${ }^{\mathrm{a}, \mathrm{b}}$ Tomas Gudbjartsson, MD, PhD, ${ }^{\mathrm{c}}$ Anders Ahlsson, MD, PhD, ${ }^{\mathrm{d}, \mathrm{e}}$ Simon Fuglsang, MD, Arnar Geirsson, $\mathrm{MD},{ }^{\mathrm{c}}$ Emma C. Hansson, $\mathrm{MD}, \mathrm{PhD},{ }^{\mathrm{g}}$ Vibeke Hjortdal, MD, PhD, ${ }^{\mathrm{f}}$ Anders Jeppsson, $\mathrm{MD}, \mathrm{PhD},{ }^{\mathrm{g}}$ Kati Järvelä, $\mathrm{MD}, \mathrm{PhD},{ }^{\text {,,i }}$ Ari Mennander, $\mathrm{MD}, \mathrm{PhD}$, , Shahab Nozohoor, MD, PhD, ${ }^{\mathrm{j}, \mathrm{k}}$ Christian Olsson, MD, PhD, ${ }^{1}$ Anders Wickbom, MD, PhD, ${ }^{\mathrm{d}, \mathrm{e}}$ Igor Zindovic, $\mathrm{MD},{ }^{\mathrm{j}, \mathrm{k}}$ and Jarmo Gunn, $\mathrm{MD}, \mathrm{PhD}^{\mathrm{a}, \mathrm{b}}$

\section{ABSTRACT}

Objectives: To describe the relationship between the extent of primary aortic repair and the incidence of reoperations after surgery for type A aortic dissection.

Methods: A retrospective cohort of 1159 patients treated for type A aortic dissection at eight Nordic low- to medium-sized cardiothoracic centers from 2005 to 2014. Data were gathered from patient records and national registries. Patients were separately divided into 3 groups according to the distal anastomoses technique (ascending aorta $[\mathrm{n}=791]$, hemiarch [ $\mathrm{n}=247]$, and total arch $[\mathrm{n}=66]$ ), and into 2 groups for proximal repair (aortic root replacement $[\mathrm{n}=285]$ and supracoronary repair $[\mathrm{n}=832])$. Freedom from reoperation was estimated with cumulative incidence survival and Fine-Gray competing risk regression model was used to identify independent risk factors for reoperation.

Results: The median follow-up was 2.7 years (range, 0-10 years). Altogether 51 out of 911 patients underwent reoperation. Freedom from distal reoperation at 5 years was $96.9 \%$, with no significant difference between the groups $(P=.22)$. Freedom from proximal reoperation at 5 years was $97.8 \%$, with no difference between the groups $(P=.84)$. Neither DeBakey classification nor the extent of proximal or distal repair predicted freedom from a later reoperation. The only independent risk factor associated with a later proximal reoperation was a history of connective tissue disease.

Conclusions: Type A aortic dissection repair in low- to medium-volume centers was associated with a low reoperation rate and satisfactory midterm survival. The extent of the primary repair had no significant influence on reoperation rate or midterm survival. (J Thorac Cardiovasc Surg 2018;156:939-48)

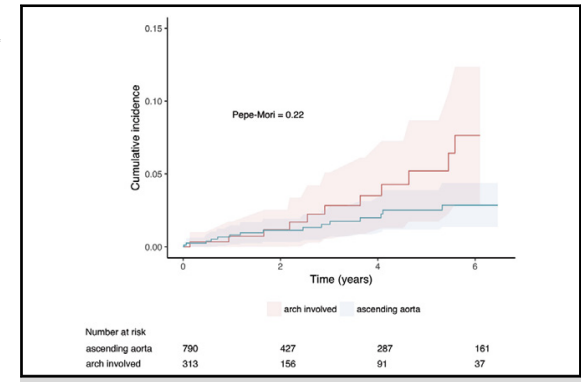

Cumulative incidence of dissection reoperations between the extent of distal anastomosis.

\section{Central Message}

The midterm reoperation rate after acute type $\mathrm{A}$ aortic dissection surgery is low. The extent of proximal or distal repair did not significantly influence the cumulative incidence of reoperation.

\section{Perspective}

Nordic Consortium for Acute Type A Aortic Dissection results show a low midterm reoperation rate and satisfactory survival with no significant differences between the different extents of primary surgery. These results are from nonhigh-volume cardiothoracic centers, and may also encourage other low-to-medium volume centers to carefully weigh achievable long-term benefits against a possibly elevated initial risk with a more radical approach.

See Editorial Commentary page 949

See Editorial page 935.

\footnotetext{
From the ${ }^{\mathrm{a}}$ Heart Center, Turku University Hospital, Turku, Finland; ${ }^{\mathrm{b}}$ Department of Surgery, University of Turku, Turku, Finland; ${ }^{\mathrm{C}}$ Landspitali University Hospital and Faculty of Medicine, University of Iceland, Reykjavik, Iceland; ${ }^{\mathrm{d}}$ Department of Cardiothoracic and Vascular Surgery, Örebro University Hospital, Orebro, Sweden; ${ }^{\mathrm{e}}$ School of Health and Medicine, Orebro University, Orebro, Sweden; ${ }^{\mathrm{f}}$ Department of Thoracic and Cardiovascular Surgery, Aarhus University Hospital, Skejby, Denmark; ${ }^{\mathrm{g}}$ Department of Molecular and Clinical Medicine, Institute of Medicine, Sahlgrenska Academy, University of Gothenburg, Gothenburg, Sweden; ${ }^{\text {h}}$ Heart

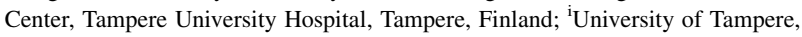
Tampere, Finland; ${ }^{j}$ Department of Cardiothoracic Surgery, Skane University Hospital, Lund, Sweden; ${ }^{\mathrm{k}}$ Clinical Sciences, Lund University, Lund, Sweden; and ${ }^{\mathrm{l} D e-}$ partment of Thoracic and Cardiovascular Surgery, Karolinska University Hospital, Stockholm, Sweden.
}

Supported by Finnish governmental research funding.

Read at the 97th Annual Meeting of The American Association for Thoracic Surgery, Boston, Massachusetts, April 29-May 3, 2017.

Received for publication April 28, 2017; revisions received Feb 6, 2018; accepted for publication March 2, 2018; available ahead of print May 9, 2018.

Address for reprints: Jarmo Gunn, MD, PhD, Department of Surgery, University of Turku, PL 52, 20521 Turku, Finland (E-mail: jarmo.gunn@tyks.fi). 0022-5223

Copyright $@ 2018$ by The American Association for Thoracic Surgery. Published by Elsevier Inc. This is an open access article under the CC BY-NC-ND license (http:// creativecommons.org/licenses/by-nc-nd/4.0/). https://doi.org/10.1016/j.jtcvs.2018.03.144 


\section{Abbreviations and Acronyms \\ ATAAD = acute type A ascending aortic dissection \\ NORCAAD $=$ Nordic Consortium for Acute Type A Aortic Dissection}

Scanning this QR code will take you to a supplemental video. To view the AATS Annual Meeting Webcast, see the URL next to the webcast thumbnail.

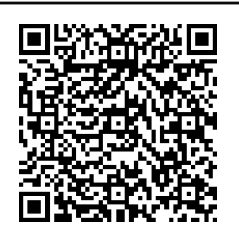

Acute type A aortic dissection (ATAAD) is an aortic emergency requiring immediate surgical intervention, reflected in high in-hospital mortality that ranges from $4.2 \%$ to $28.6 \%$ in previous studies. ${ }^{1-4}$ For those who survive the initial critical period, the long-term actuarial survival up to 10 years is reported to be in the $53.4 \%$ to $65.0 \%$ range, and mainly influenced by general cardiovascular risk factors. $^{5-9}$

For the past 2 decades, large multinational databases have been created to evaluate different surgical approaches for ATAAD and their influence on complications and outcomes. The most extensive ones are the International Registry of Acute Aortic Dissection and The German Registry for Acute Aortic Dissection Type A. ${ }^{1,10}$ A more recent large, multicenter database is the Nordic Consortium for Acute Type A Aortic Dissection (NORCAAD), which consists of 8 small- to medium-sized cardiothoracic centers in University Hospitals in Sweden, Denmark, Finland, and Iceland. So far, a total of 1159 consecutive ATAAD cases from 2005 to 2014 have been included in the NORCAAD registry. $^{11}$

Most studies on ATAAD in the literature are either single center studies with small patient cohorts or larger studies with focus mainly on short-term complications and 30day or in-hospital mortality following surgical repair. ${ }^{8}$ However, studies on mid- and long-term outcomes, including evaluation of complications, later reoperation on the aortic valve and aorta and also morbidity, are more uncommon. According to available reports, between $8.7 \%$ and $13.5 \%$ of patients require a cardiovascular reoperation following the immediate postoperative period of a ATAAD repair. ${ }^{12-16}$ These reoperations are often technically challenging with a high initial mortality and morbidity. There is scarce information on risk factors for late reoperations, which is important when these patients are being followed-up clinically. Furthermore, few previous studies have investigated whether the surgical approach at the primary operation influences the rate of late reoperations after ATAAD. In this substudy of NORCAAD, we therefore investigated proximal and distal reoperations after midterm follow-up, and evaluated the association between the extent of the primary repair and later reoperations.

\section{MATERIALS AND METHODS \\ Patient Population}

The cohort for this study is from the NORCAAD study. The NORCAAD study design has been described previously. ${ }^{11}$ The population at risk is estimated at 9,500,000 inhabitants. Consecutive patients $(\mathrm{n}=1159)$ who underwent surgery for ATAAD in 8 academic cardiothoracic centers between January 1, 2005, and December 31, 2014, have been included in the registry. Patient information was collected retrospectively from hospital records and mortality data gained from national population registries. Each center was responsible for its own patient data collection and for approval from its ethical committee. There were incomplete data for reoperations and/or regarding the extent of primary surgery in 28 patients, leaving 1131 cases for analysis.

\section{Definitions}

The definition of an ATAAD was a dissection involving the ascending aorta with or without involvement of the arch and descending aorta, and for which surgery was performed within 2 weeks from the first symptoms. ATAAD was divided into DeBakey type I and II; DeBakey I involved the descending aorta and in DeBakey II, the dissection ended before the innominate artery. Pseudoaneurysms were defined as aneurysms formed adjacent to sutures lines. An anastomosis between the tubular part of a vascular prosthesis and the aorta sutured under direct vision during circulatory arrest were defined as an open-distal anastomosis, and clamp-on anastomosis as an anastomosis performed with an aortic crossclamp distal to the suture line.

\section{Primary Surgery}

We defined each primary surgical procedure into 1 of the following categories: distal repair was classified as the ascending aorta only (distal anastomosis proximal to the origin of the innominate artery), hemiarch replacement (resection of the underside of the arch not requiring arch vessel reimplantation), and total arch replacement (distal anastomosis extending distal to the left subclavian artery with arch vessel reimplantation either separately or as islands). Proximal repair was classified as isolated supracoronary replacement with or without valve resuspension or surgery involving the aortic root (composite valve and conduit; that is, Bentall procedure, separate valve remodeling, or valve reimplantation like Yacoub or David procedure). For the cumulative incidence analysis we combined hemiarch and total arch replacement groups because there were few events in the latter group.

\section{Reoperation}

Any reoperation was defined as any cardiac or aortic surgery that could be related to primary ATAAD repair, excluding reoperations due to bleeding. The main indications for a reoperation in the different centers were similar during the whole study period and mainly included an aneurysm or a pseudoaneurysm formation exceeding $55 \mathrm{~mm},>10 \mathrm{~mm}$ aortic diameter increase/year, endocarditis, graft infection, or severe aortic regurgitation. All decisions of reoperation were based on the individual patient's risk profile as well as local protocols and competence.

\section{Follow-up}

The protocol in all 8 centers generally consisted of a computed tomography scan of the aorta at 1 to 3 months postoperatively, then at 1 year 
postoperatively, and afterward yearly or more often if there were signs of complications or rapid growth of the aorta. Detailed imaging data or follow-up measurements of aortic diameters were not available.

\section{Statistics}

Basic analyses were performed with IBM SPSS Statistics version 24 (IBM-SPSS Inc, Armonk, NY). The groups were compared using the $\chi^{2}$ test. Cumulative incidence curves and Fine-Gray competing risk regression analyses were performed using Stata/IC15.0 for Windows (StataCorp, College Station, Tex). Type of proximal surgery (supracoronary repair or aortic valve inclusive) and type of distal surgery (distal anastomosis in ascending aorta, hemiarch, or total arch) were entered into Fine-Gray competing risk regression model and adjusted for connective tissue disease and DeBakey classification. Hazard ratios were reported with $95 \%$ confidence intervals. Cumulative incidence of reoperations was shown as curves and the groups were compared using Pepe-Mori test with death as a competing risk event.

\section{RESULTS}

\section{General}

Mean follow-up was 3.3 years (median, 2.7 years; range, 0-10 years), resulting in a total follow-up time of 3718 patient-years. The mean age of patients was $61.6 \pm 12.1$ years (median 63.0 years; $95 \%$ confidence interval, 60.9-62.3 years), and $757(66.9 \%)$ were men. The baseline characteristics are shown in Table 1.

\section{Primary Aortic Repair}

Most of the dissections continued to the descending part of the thoracic aorta (DeBakey I 73.8\% vs DeBakey II $26.2 \%$ ). During the primary surgical procedure, 832 $(73.7 \%)$ of proximal repairs were isolated supracoronary replacements, of which $450(53.3 \%)$ had concomitant aortic valve resuspension, $285(25.2 \%)$ had root replacement or an aortic valve-sparing procedure, and in 12 patients $(1.1 \%)$ the procedure was attempted at the very beginning. Patients who underwent aortic root surgery had significantly more connective tissue disease $(9.9 \%$ vs $3.0 \% ; P<.01)$ and a bicuspid aortic valve $(14.8 \%$ vs $3.0 \% ; P<.01)$. Open distal anastomosis was performed significantly more often in the isolated supracoronary group $(75.4 \%$ vs $88.3 \% ; P<.01)$ (Table 2$)$.

The majority of distal anastomoses, 791 (70.6\%), were located in the ascending aorta, 247 (22.0\%) underwent hemiarch repair, only 66 patients $(5.9 \%)$ had total arch repair, and $17(1.5 \%)$ had an attempted procedure. The total arch repair group more commonly had connective tissue disease $(4.8 \%$ vs $2.8 \%$ vs $12.1 \% ; P=.01)$ and experienced a postoperative stroke following the primary repair $(17.9 \%$ vs $18.4 \%$ vs $33.3 \% ; P=.01$ ) (Table 3 ).

\section{Reoperations}

There were 26 proximal reoperations and 30 distal reoperations performed on a total of 51 patients. Five patients had reoperations on both proximal and distal aorta, 3 patients with both procedures performed simultaneously and 2 of them had reoperations on 2 separate occasions. Most
TABLE 1. Patient characteristics

\begin{tabular}{|c|c|c|}
\hline Variable & $\mathbf{N}$ & Result \\
\hline Age & 1131 & $61.6 \pm 12.1$ \\
\hline Male gender & 1131 & $757(66.9)$ \\
\hline Active smoking & 1064 & $256(24.0)$ \\
\hline $\begin{array}{l}\text { Family history of } \\
\text { Aortic dissection } \\
\text { Thoracic aortic aneurysm }\end{array}$ & $\begin{array}{l}807 \\
807\end{array}$ & $\begin{array}{l}62(7.7) \\
38(4.7)\end{array}$ \\
\hline \multicolumn{3}{|l|}{ Clinical background } \\
\hline Bicuspid aortic valve* & 1119 & $66(5.9)$ \\
\hline Connective tissue disease & 1127 & $53(4.7)$ \\
\hline Marfan Syndrome & 1127 & $46(4.1)$ \\
\hline Hypertension & 1129 & $587(52.0)$ \\
\hline Untreated hypertension & 746 & $65(8.7)$ \\
\hline Chronic obstructive pulmonary disease & 1127 & $67(5.9)$ \\
\hline Extent of dissection & 1131 & \\
\hline DeBakey type I & & $829(73.3)$ \\
\hline DeBakey type II & & $294(26.0)$ \\
\hline Any preoperative malperfusion & 1123 & $314(28.0)$ \\
\hline \multicolumn{3}{|l|}{ Intraoperative variables } \\
\hline Open distal anastomoses & 1125 & $952(84.6)$ \\
\hline Glue used & 1035 & $312(30.1)$ \\
\hline Felt used & 911 & $617(67.7)$ \\
\hline Perioperative myocardial infarction* & 1098 & $71(6.5)$ \\
\hline \multicolumn{3}{|l|}{ Primary tear } \\
\hline Excision & 918 & $855(93.1)$ \\
\hline Location & 927 & \\
\hline Root & & $143(15.4)$ \\
\hline Ascending & & $652(70.3)$ \\
\hline Ascending and arch & & $6(0.6)$ \\
\hline Arch & & $114(12.3)$ \\
\hline Descending & & $12(1.3)$ \\
\hline \multicolumn{3}{|l|}{ Postoperative variables } \\
\hline Major complication $\dagger$ occurred & 1118 & $532(47.6)$ \\
\hline Postoperative stroke & 1102 & 205 (18.6) \\
\hline Resternotomy for bleeding & 1100 & $232(21.1)$ \\
\hline Deep sternal wound infection & 1100 & $24(2.2)$ \\
\hline Reoperations & 1132 & $51(4.5)$ \\
\hline Proximal reoperations & & $26(2.3)$ \\
\hline Distal reoperations & & $30(2.7)$ \\
\hline
\end{tabular}

Values are presented as mean \pm standard deviation or $\mathrm{n}(\%)$. *New left ventricular bundle branch block, Q-waves on electrocardiography, or creatine kinase-MB > 70. $\dagger$ Reoperation for bleeding or revision, deep sternal wound infection, acute renal failure requiring dialysis, respiratory failure requiring tracheostomy, stroke, or postoperative myocardial infarction.

of the reoperations were elective (37 out of $53 ; 69.8 \%$ ); the others were either urgent or emergent (16 out of 53 ; $30.2 \%$ ).

The proportion of patients who underwent proximal reoperations was comparable for patients with root replacement/valve sparing or supracoronary repair $(1.8 \%$ vs $2.5 \% ; P=.65)$ as proximal extent of the primary surgery (Table 2). Similarly, there was no difference in the proportion of patients who underwent distal reoperations based on 
TABLE 2. Characteristics according to the extent of proximal repair

\begin{tabular}{llcc}
\hline \multicolumn{1}{c}{ Variable } & $\begin{array}{c}\text { Root } \\
\text { replacement } \\
(\mathbf{n}=\mathbf{2 8 5})\end{array}$ & $\begin{array}{c}\text { Supracoronary } \\
\text { repair } \\
(\mathbf{n = 8 3 2})\end{array}$ & $\boldsymbol{P}$ value \\
\hline Female sex & $67(23.5)$ & $301(36.2)$ & $<.001$ \\
Connective tissue disease & $28(9.9)^{*}$ & $25(3.0) \dagger$ & $<.001$ \\
\hline Bicuspid valve & $42(14.8)^{*}$ & $24(2.9) \ddagger$ & $<.001$ \\
Open distal anastomoses & $214(75.4 \%)^{*}$ & $734(88.3) \S$ & $<.001$ \\
\hline Proximally later reoperated & $5(1.8)$ & $21(2.5)$ & .649 \\
\hline
\end{tabular}

Values are presented as $\mathrm{n}(\%) . *$ Sample size $=284 . \dagger$ Sample size $=829 . \dagger$ Sample size $=822$. $\S$ Sample size $=831$.

different extent of the distal anastomosis performed: $2.3 \%$ for ascending aorta only, $4.0 \%$ for hemiarch, and $3.0 \%$ for total $\operatorname{arch}(P=.32)$ (Table 3).

Freedom from any reoperation was $98.2 \%, 95.0 \%$, and $92.3 \%$ at 1,5 , and 8 years, respectively. Freedom from proximal reoperation was $98.9 \%, 97.8 \%$, and $96.1 \%$ at 1,5 , and 8 years and freedom from distal reoperation were $99.2 \%, 96.9 \%$, and $94.7 \%$ at 1,5 , and 8 years, respectively. The cumulative survival of patients who underwent a reoperation was $98.0 \%, 92.8 \%$, and $88.2 \%$ at 1,5 , and 8 years, respectively (Figure 1 ).

\section{Proximal Reoperations}

Proximal reoperations consisted of valve conduit graft replacements (Bentall procedure) in 16 patients $(61.5 \%)$, valve sparing root reconstructions with coronary reimplantations or remodeling (David or Yacoub procedures) in 4 patients $(15.4 \%)$, isolated supracoronary repair in 3 patients $(11.5 \%)$, isolated aortic valve replacement in 1 patient $(3.8 \%), 1$ repair of ruptured anastomosis $(3.8 \%)$, and 1 procedure that remained uncertain $(3.8 \%)$. The principal indications for proximal reoperations were severe aortic regurgitation $(\mathrm{n}=12 ; 46.2 \%)$ and development of root aneurysm or a proximal pseudoaneurysm $(n=9 ; 34.6 \%)$; other indications were graft infection $(\mathrm{n}=2 ; 7.7 \%)$, endocarditis $(\mathrm{n}=1 ; 3.8 \%)$, rupture of the anastomosis $(\mathrm{n}=1$; $3.8 \%)$, residual dissection in the root $(\mathrm{n}=1 ; 3.8 \%)$, and root dissection $(\mathrm{n}=1 ; 3.8 \%)$. In 7 cases, patients had an additional indication for reoperation (Table 4). There was no significant difference in the risk of proximal reoperation between the primary root replacement group or patients operated with a supracoronary graft technique $(98.6 \%$, $97.4 \%$, and $97.4 \%$ vs $98.7 \%, 97.2 \%$, and $93.8 \%$ at 1,5 , and 8 years, respectively; $P=.84$ ).

\section{Distal Reoperations}

Most distal reoperations were thoracoabdominal aortic aneurysm repair $(\mathrm{n}=19 ; 63.3 \%)$, of which 4 were a thoracic endovascular aortic repair, 3 were a combination of thoracic endovascular aortic repair and open repair, and the remaining 12 were open repairs. Others were total
TABLE 3. Characteristics according to the extent of distal repair

\begin{tabular}{llllr}
\hline \multicolumn{1}{c}{ Variable } & $\begin{array}{c}\text { Ascending } \\
\text { aorta } \\
(\mathbf{n}=\mathbf{7 9 1})\end{array}$ & $\begin{array}{c}\text { Hemiarch } \\
(\mathbf{n = 2 4 7 )}\end{array}$ & $\begin{array}{c}\text { Total } \\
\text { arch } \\
(\mathbf{n = 6 6 )}\end{array}$ & $\begin{array}{c}\boldsymbol{P} \\
\text { value }\end{array}$ \\
\hline $\begin{array}{c}\text { Connective tissue } \\
\text { disease }\end{array}$ & $38(4.8)^{*}$ & $7(2.8)$ & $8(12.1)$ & .007 \\
$\begin{array}{c}\text { Open distal } \\
\text { anastomosis }\end{array}$ & $636(80.5)^{*}$ & $242(98.0)$ & $59(89.4)$ & $<.001$ \\
$\begin{array}{c}\text { Postoperative } \\
\text { stroke }\end{array}$ & $138(17.9 \%) \dagger$ & $45(18.4 \%) \ddagger$ & $21(33.3) \S$ & .010 \\
$\begin{array}{c}\text { Distally later } \\
\text { reoperated }\end{array}$ & $18(2.3)$ & 10 & $2(3.0)$ & .322 \\
\hline
\end{tabular}

$\overline{\text { Values are presented as } \mathrm{n}(\%) . * \text { Sample size }=791 . \dagger \text { Sample size }=772 . \ddagger \text { Sample }}$ size $=244$. $\S$ Sample size $=63$.

arch replacements $(n=7 ; 23.3 \%)$, of which 3 had concomitant frozen elephant trunk and 1 traditional elephant trunk procedure, and hemiarch repair $(\mathrm{n}=3 ; 10.0 \%)$. The most common indication for reoperation was thoracoabdominal aortic aneurysm $(\mathrm{n}=18 ; 60.0 \%)$, followed by pseudoaneurysm $(\mathrm{n}=9 ; 30.0 \%)$ and graft infection $(\mathrm{n}=1$; $3.3 \%$ ) (Table 4).

No statistical differences were observed between the distribution of DeBakey type I or II and the risk for late distal reoperations. Freedom from distal reoperation was $98.4 \%$, $94.5 \%$, and $91.5 \%$ at 1,5 , and 8 years for DeBakey type I, respectively, and $97.7 \%, 96.5 \%$, and $95.2 \%$ at 1,5 , and 8 years for DeBakey II, respectively $(P=.57)$ (Figure 2$)$. Freedom from distal reoperation according to the type of distal anastomosis during primary surgery at 1, 5, and 8 years was $99.2 \%, 97.5 \%$, and $95.3 \%$ for ascending aorta and $99.3 \%, 94.8 \%$, and $92.4 \%$ for arch involvement, respectively, with no significant differences observed between the groups $(P=.22)$ (Figure 3$)$.

\section{Survival After Reoperation}

Altogether, 5 deaths $(9.8 \%)$ were registered after reoperation during the follow-up period. Two patients had aortic rupture, 1 patient had fulminant sepsis, another 1 experienced a massive postoperative stroke, and the fifth patient died of postoperative multiorgan failure (Table 5).

\section{Risk Factors for a Reoperation}

In the Fine-Gray multivariable competing risk regression model, the extent of the distal or proximal repair was not associated with the risk of a reoperation, but a history of connective tissue disease independently predicted a proximal reoperation (hazard ratio, $4.99 ; 95 \%$ confidence interval, $1.80-13.85 ; P<.01)$.

\section{DISCUSSION}

The main findings of this study were that the overall reoperation rate after acute type A aortic dissection was lower 


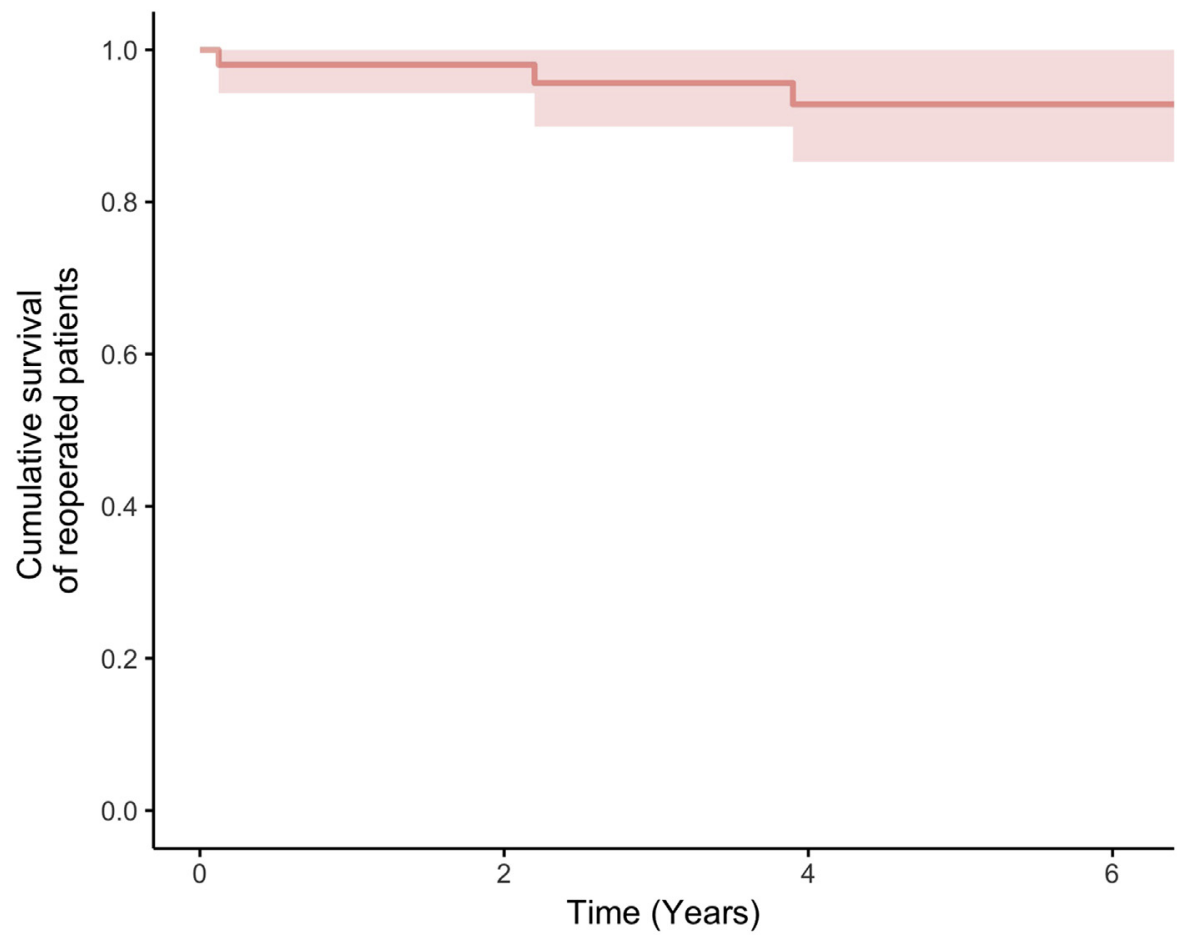

Number at risk

All reoperated pat. 51

43

33

22

FIGURE 1. Cumulative survival in type A aortic dissection patients who underwent reoperation.

than in most contemporary series; mortality after reoperations was low; and connective tissue disease was independently associated with reoperation after acute type A aortic dissection repair (Video 1).
The cumulative incidence of late reoperations in the present series, $5.0 \%$ at 5 years, was lower than in previous studies that have reported an incidence in the $6 \%$ to $18 \%$ range at 5 years. ${ }^{12,15,17}$ There are several possible

TABLE 4. Reoperation procedures in 51 patients. Five patients had both proximal and distal reoperations

\begin{tabular}{|c|c|c|c|c|c|c|c|}
\hline \multicolumn{3}{|c|}{ Proximal reoperation $(n=26)$} & & \multicolumn{3}{|c|}{ Distal reoperation $(n=30)$} & \\
\hline Indication & & Procedures & & Indication & & Procedures & \\
\hline Severe AI & 12 & Composite graft & 16 & TAAA & 18 & TAAA repair & 19 \\
\hline+ Graft infection & $(2)^{*}$ & Valve sparing root replacement & 4 & Pseudo-aneurysm & 9 & -TEVAR & $(4) *$ \\
\hline $\begin{array}{l}\text { Root dilatation or } \\
\text { pseudoaneurysm }\end{array}$ & 9 & Supracoronary repair & 3 & Graft infection & 1 & $\begin{array}{l}\text { - Combination of TEVAR and } \\
\text { open repair }\end{array}$ & (3)* \\
\hline + Endocarditis & $(2)^{*}$ & Isolated AVR & 1 & Others & 2 & Hemiarch repair & 3 \\
\hline+ Severe AI & $(1)^{*}$ & Repair of anastomosis & 1 & & & Total arch repair & 7 \\
\hline Graft infection & 2 & Unknown & 1 & & & + frozen elephant & $(3)^{*}$ \\
\hline Endocarditis & 1 & & & & & trunk & $(1)^{*}$ \\
\hline+ Root dilatation & $(1)^{*}$ & & & & & + traditional elephant trunk & \\
\hline Anastomotic rupture & 1 & & & & & Other & 1 \\
\hline Root dissection & 1 & & & & & & \\
\hline+ severe AI, graft infection & $(1)^{*}$ & & & & & & \\
\hline
\end{tabular}




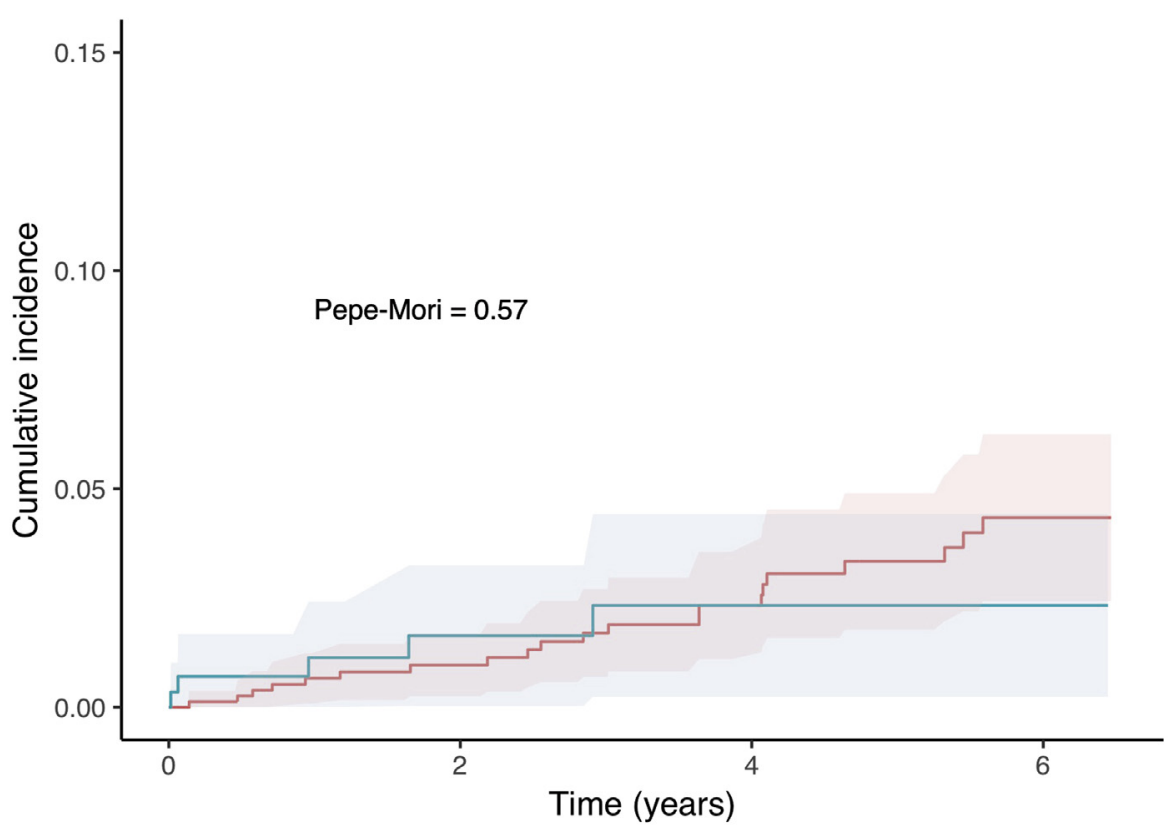

DeBakey type I DeBakey type II

Number at risk

DeBakey type I

DeBakey type II
829

294
450

142
302

81
163

39

FIGURE 2. Cumulative incidence of reoperations after type A aortic dissection surgery stratified by DeBakey classification. There was no significant difference between the groups $(P=.57)$.

explanations to the low reoperation rate in the present study. First of all, a consistent trend in reports from larger studies on ATAAD is the improvement of outcomes over the decades, which could infer that the infrequency of reinterventions in the NORCAAD study merely reflect contemporary results in aortic surgery and is not an aberrance. ${ }^{1,7,10,18}$ However, a direct comparison is difficult because the cohort and the definition of a reoperation might differ between studies. The decision to undertake a reoperation is highly dependent on the surgeon's individual opinion and experience, which might in part explain higher reoperation rates in larger, specialized centers. It is also not evident what the treatment delays are in different studies, which could result in different sample populations. One should also take into account that this was a midterm follow-up; therefore, it can be speculated that more reoperations may appear as follow-up continues.

We were unable to identify any significant difference in reoperation rates between different primary repair techniques. This is in line with Wang and colleagues, ${ }^{19}$ who reported no difference in mortality or reoperation rate between primary procedure types. Many surgeons consider liberal use of more extensive surgery protective against late reoperations. Furthermore, some previous studies have suggested that an initial aggressive approach, such as total arch repair and additional elephant trunk technique reduces the risk for reoperation without increasing early mortality. ${ }^{2,11,17,20-22}$ On the other hand, other authors have advocated that extensive primary surgery during ATAAD increases patients' time under total circulatory arrest leading to a significantly increased intrahospital morbidity, such as neurologic complications, and even increased in-hospital mortality., 2,3 Consequently, the optimal extent of distal anastomosis or the role of an aggressive proximal repair during the primary surgery is not clear and a strict generalizable protocol is not easily constructed.

Although we cannot rule out possible late benefits from a more aggressive primary approach on the aorta, our results suggest that at least the differences are not dramatic and the risk incurred by late reoperations is not prohibitive, thereby justifying a less aggressive primary approach followed by watchful waiting. However, it can be speculated that techniques aimed at a larger part of the residual aorta (eg, frozen elephant trunk) could have prevented the development of 


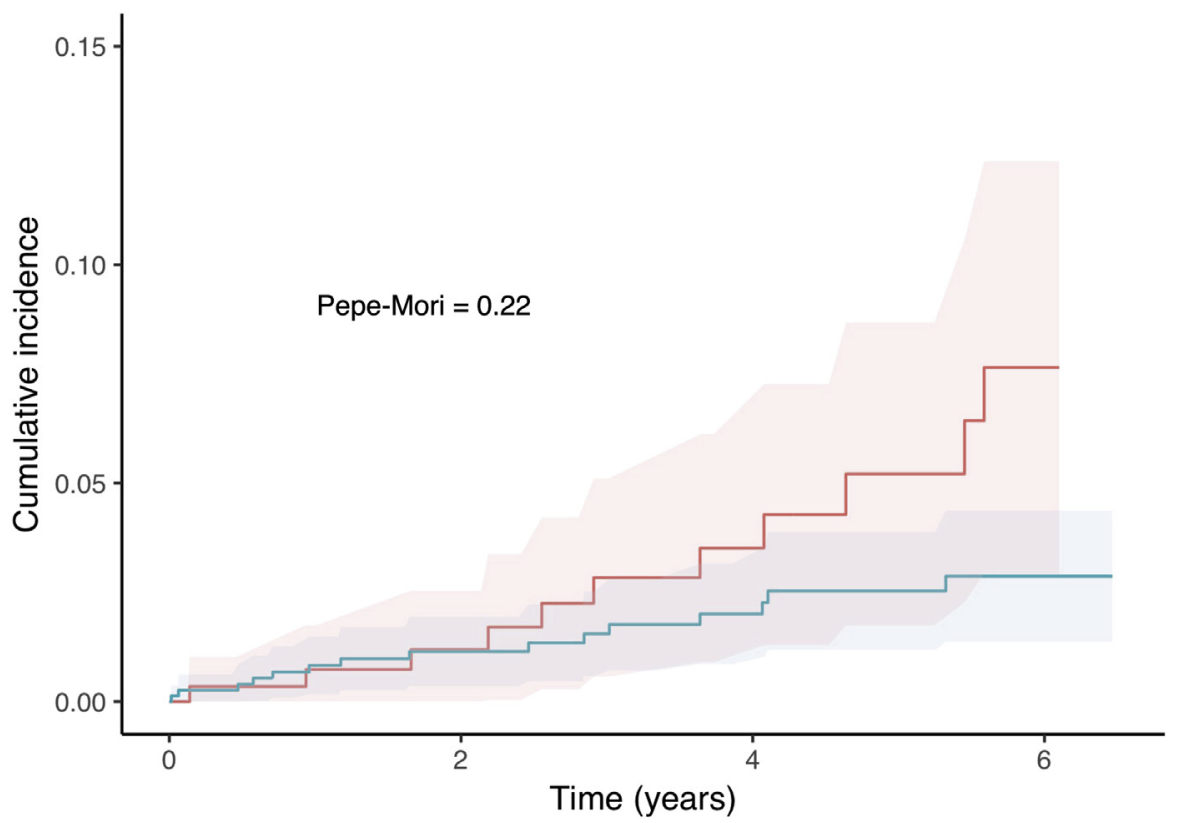

arch involved ascending aorta

Number at risk

ascending aorta $\quad 790$

313

427

287

161

arch involved

156

91

37

FIGURE 3. Cumulative incidence of reoperations after type A aortic dissection surgery according to the initial extent of distal surgery. There were no statistically significant differences between distal anastomosis in ascending aorta or involving the arch (hemiarch or total arch replacement) $(P=.22)$

thoracoabdominal aortic aneurysms and perhaps further improved survival and freedom from reintervention after ATAAD surgery.

In the present study, connective tissue disease was the only risk factor for a later proximal reoperation. Patients with connective tissue diseases were at a 5.0-times higher risk of requiring a proximal reoperation than those who do not have the disease $(P<.01)$. The extent of the dissection (DeBakey class) was not associated with later reoperations. It could be speculated that in cases where particularly the primary tear could not be identified or resected, the extent of propagation of the dissection (DeBakey class) might predict later complications. However, the numbers of these patients in the present study preclude meaningful analyses on this subject. No other significant factors were found for proximal or distal reoperations. These results may reflect the great heterogeneity in the actual clinical presentation and morphology of dissections, which makes detailed classification difficult.

TABLE 5. Deaths after reoperations

\begin{tabular}{|c|c|c|c|c|c|}
\hline \multirow[b]{2}{*}{ Patient no. } & \multicolumn{2}{|c|}{ Proximal reoperation } & \multicolumn{2}{|c|}{ Distal reoperation } & \multirow[b]{2}{*}{ Cause of death } \\
\hline & Indication & Procedure & Indication & Procedure & \\
\hline 1 & Graft infection & Valve sparing root replacement & - & - & Aortic rupture \\
\hline 2 & - & - & TAAA & Total arch replacement & Postoperative stroke \\
\hline 3 & - & - & TAAA & $\begin{array}{l}\text { Combination of TEVAR } \\
\text { and open repair }\end{array}$ & Sepsis \\
\hline 4 & - & - & TAAA & $\begin{array}{l}\text { Combination of TEVAR } \\
\text { and open repair }\end{array}$ & Postoperative multiorgan failure \\
\hline 5 & $\begin{array}{c}\text { Root aneurysm, } \\
\text { endocarditis }\end{array}$ & Valve sparing root replacement & TAAA & TEVAR & Aortic rupture \\
\hline
\end{tabular}

TAAA, Thoracoabdominal aortic aneurysm; TEVAR, thoracic endovascular aortic repair. 


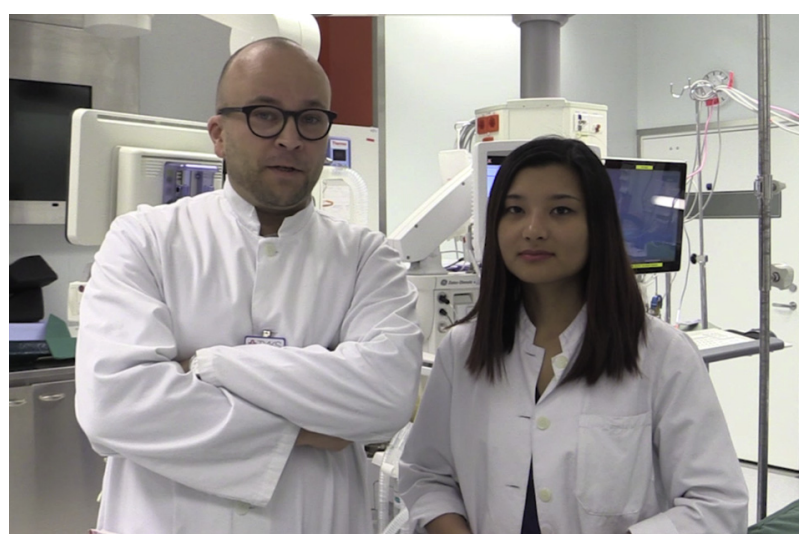

VIDEO 1. The authors discussing the research. Video available at: https:// www.jtcvs.org/article/S0022-5223(18)30932-2/fulltext.

The survival of patients undergoing reoperation was satisfying. This could be explained by selection bias because patients with a high comorbidity burden and consequently high mortality risk are more often denied reoperations. It is also noteworthy that the incidence of annual ATAAD operations in the NORCAAD registry has significantly increased from 85 in 2005 to 150 in $2014 .{ }^{18}$ Therefore, most patients in the registry are from the past 3 years, which also explains the relatively short median follow-up time. A longer follow-up period would be preferable to further survey the incidence and survival of patients undergoing reoperations.

\section{Strengths and Limitations}

The strengths of our present study include the homogenous study population and health care system, and the very comprehensive follow-up data regarding reoperations and mortality. Limitations include the retrospective study design, different criteria for reoperations among institutions and surgeons, paucity of radiologic data, relatively short follow-up time, and the limited size of the study cohort. This infers a significant risk of type II errors.

\section{CONCLUSIONS}

This retrospective midterm follow-up study from 8 smallto medium-sized Nordic cardiothoracic centers showed that the risk of reoperation after ATAAD was low. Furthermore, a more extensive distal repair (arch involvement vs ascending aorta) did not abolish the need for reintervention. However, patients with connective tissue disease may need closer follow-up after ATAAD surgery and a lower threshold for a more radical primary proximal operation may be indicated. The primary extent of aortic repair during ATAAD needs to be carefully evaluated on a case-by-case basis.

\section{Webcast}

You can watch a Webcast of this AATS meeting presentation by going to: https://aats.blob.core.windows.net/ media/17AM/2017-05-02/RM311/05-02-17_Room311_1623_ Pan.mp4.

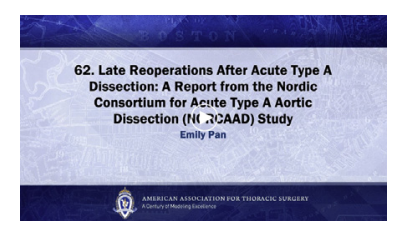

\section{Conflicts of Interest Statement}

Authors have nothing to disclose with regard to commercial support.

\section{References}

1. Tsai TT, Evangelista A, Nienaber CA, Trimarchi S, Schtem U, Fattori R, et al Long-term survival in patients presenting with type A acute aortic dissection: in sights from the international registry of acute aortic dissection (IRAD). Circulation. 2006;114:I350-6.

2. Shi E, Gu T, Yu Y, Yu L, Wang C, Fang Q, et al. Early and midterm outcomes of hemiarch replacement combined with stented elephant trunk in the management of acute DeBakey type I aortic dissection: comparison with total arch replacement. J Thorac Cardiovasc Surg. 2014;148:2125-31.

3. Rylski B, Beyersdorf F, Kari FA, Schlosser J, Blanke P, Siepe M. Acute type A aortic dissection extending beyond ascending aorta: limited or extensive distal repair. J Thorac Cardiovasc Surg. 2014;148:949-54.

4. Pagni S, Ganzel BL, Trivedi JR, Singh R, Mascio CE, Austin EH, et al. Early and midterm outcomes following surgery for acute type A aortic dissection. J Card Surg. 2013;28:543-9.

5. Bekkers JA, Raap GB, Takkenberg JJ, Bogers AJ. Acute type A aortic dissection: long-term results and reoperations. Eur J Cardiothorac Surg. 2013;43 2S389-96.

6. Larsen M, Bartnes K, Tsai TT, Eagle KA, Evangelista A, Nienaber CA, et al. Extent of preoperative false lumen thrombosis does not influence long-term survival in patients with acute type A aortic dissection. J Am Heart Assoc. 2013;2: $\mathrm{e} 000112$.

7. Olsson C, Ahlsson A, Fuglsang S, Geirsson A, Gunn J, Hansson EC, et al. Medium-term survival after surgery for acute type A aortic dissection is improving. Eur J Cardiothorac Surg. 2017;52:852-7.

8. Roselli EE, Loor G, He J, Rafaek AE, Raheswaran J, Houghtaling PL, et al. Distal aortic interventions after repair of ascending dissection: the argument for a more aggressive approach. J Thorac Cardiovasc Surg. 2015; 149:S117-24.

9. Olsson C, Hillebrant CG, Liska J, Lockowandt U, Eriksson P, Franco-Cereced A. Mortality and reoperations in survivors operated on for acute type A aortic dissection and implications for catheter-based or hybrid interventions. $J$ Vasc Surg. 2013;58:333-9.

10. Boening A, Karck M, Conzelmann LO, Easo J, Kruger T, Rylskki B, et al. German registry for acute aortic dissection type A: structure, results, and future perspectives. Thorac Cardiovasc Surg. 2017;65:77-84.

11. Geirsson A, Ahlsson A, Franco-Cereceda A, Fuglsang S, Gunn J, Hansson EC, et al. The Nordic Consortium for acute type A aortic dissection (NORCAAD): objectives and design. Scand Cardiovasc J. 2016;50:5-6. 334-40.

12. Geirsson A, Bavaria JE, Swarr D, Keane MG, Woo YJ, Wy Szeto, et al. Fate of the residual distal and proximal aorta after acute type a dissection repair using a contemporary surgical reconstruction algorithm. Ann Thorac Surg. 2007;84: 1955-64.

13. Kobuch R, Hilker M, Rupprecht L, Hirt S, Keyser A, Puehler T, et al. Late reoperations after repaired acute type A aortic dissection. J Thorac Cardiovasc Surg. 2012;144:300-7.

14. Nishi H, Mitsuno M, Tanaka H, Ryomoto M, Fukui S, Miyamoto Y. Late reoperations after repair of acute type A aortic dissection. J Card Surg. 2010;25: $208-13$. 
15. Pugliese P, Pessotto R, Santini F, Montalbano G, Luciani GB, Mazzucco A. Risk of late reoperations in patients with acute type A aortic dissection: impact of a more radical surgical approach. Eur J Cardiothorac Surg. 1998;13:576-81.

16. Dell'Aquila AM, Pollari F, Fattouch K, Santarpino G, Hillebrand J, Schneider S, et al. Early outcomes in re-do operation after acute type A aortic dissection: results from the multicenter REAAD database 2016. Heart Vessels. 2017;32: 566-73.

17. Concistre G, Casali G, Santaniello E, Montalto A, Fiorani B, Dell'Aquila A, et al. Reoperation after surgical correction of acute type A aortic dissection: risk factor analysis. Ann Thorac Surg. 2012;93:450-6.

18. Geirsson A, Ahlsson A, Franco-Cereceda A, Fuglsang S, Gunn J, Hansson EC, et al. Hospital volumes and later year of operation correlates with better outcomes in acute Type A aortic dissection. Eur J Cardiothorac Surg. 2018;53: 276-81.

19. Wang Z, Greason KL, Pochettino A, Schaff HV, Suri RM, Stulak JM, et al. Longterm outcomes of survival and freedom from reoperation on the aortic root or valve after surgery for acute ascending aorta dissection. I Thorac Cardiovasc Surg. 2014;148:2117-22.

20. Moon MR, Sundt TM III, Pasque MK, Barner HB, Huddleston CB, Damiano RJ, et al. Does the extent of proximal or distal resection influence outcome for type A dissections? Ann Thorac Surg. 2001;71:1244-50.

21. Kimura N, Itoh S, Yuri K, Adachi K, Matsumoto H, Yamaguchi A, et al. Reoperation for enlargement of the distal aorta after initial surgery for acute type A aortic dissection. J Thorac Cardiovasc Surg. 2015;149: 91-8.ei.

22. Malvindi PG, van Putte BP, Sonker U, Heijmen RH, Schepens MA, Morshuis WJ. Reoperation after acute type a aortic dissection repair: a series of 104 patients. Ann Thorac Surg. 2013;95:922-8.

Key Words: aortic dissection, reoperation, midterm, outcome

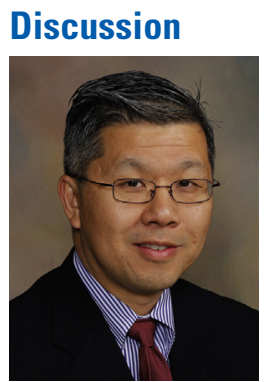

Dr Edward Chen (Atlanta, Ga). I would like to congratulate Dr Pan and her colleagues on their attempt to gain more insight into the risk factors for aortic reoperations following initial type A repair. Large observational studies such as these certainly allow for general tends to be detected, but some of the weaknesses are the difficulty in drawing any firm conclusions that might guide future practice management because of lack of data regarding specific surgical strategies performed at the initial operation. This is particularly relevant for type A dissection because of the innumerable variables that exist regarding anatomy, clinical presentation, patient comorbidities, and surgeon experience.

I have 3 questions. How were the cases distributed over the 8 sites of data collection, were the reoperations performed that followed the primary procedures equally distributed across the 8 sites in a similar manner, or were there differences based on surgeon or center experience?

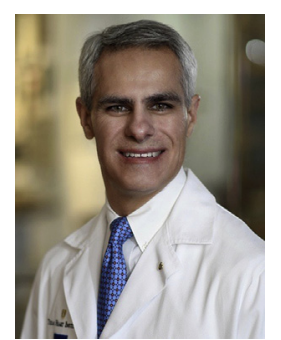

Dr Emily Pan (Turku, Finland). Thank you very much, Dr Chen. We are very privileged to have you as a discussant today.

Regarding your first question, the numbers of primary cases were actually quite evenly distributed in different centers relative to each center's catchment area size; however, there was quite a degree of variance between the centers in the choice of primary repair. For example, the frequency of total arch replacements varied between $2 \%$ and $17 \%$ and for a root replacement it varied from $13 \%$ to $30 \%$, except for 1 center that had $70 \%$. There was a trend noted that larger centers had less aggressive approaches; however, it is also of note that even 2 larger centers in our study had approximately 25 cases per year and the smaller centers had $<5$ cases per year. These are very small centers, and the differences between centers are very hard to analyze because of small numbers. And as you also well stated, it is almost impossible to know all the specifics of individual dissections.

Dr Chen. In terms of the 22 patients who underwent thoracoabdominal repair following the initial primary repair of the type A, do you know what types of proximal arch reconstruction were done in those 22 patients compared with those who perhaps did not have thoracoabdominal repair afterward? Was there a higher percentage of ascending or hemiarch or total arch or were there any differences in management initially?

Dr Pan. The distribution among those patients was quite similar in all cohorts. It was about 60 for ascending, about 40 for hemiarch, and something like 5 for total arch.

Dr Chen. Given the findings of independent analysis, particularly with respect to connective tissue disease and the increased risk of late reoperation, could you guess what measures you might take to prevent the need for future intervention based on those data?

Dr Pan. Based on our findings, I think for those who have connective tissue disease there should be a lower threshold for a more radical primary repair and for those who have had initial cardiac reoperation more intense follow-up should be indicated. In case there is a need for reoperation, one can perform it on time and avoid emergent situations.

Dr Chen. Thank you. Congratulations.

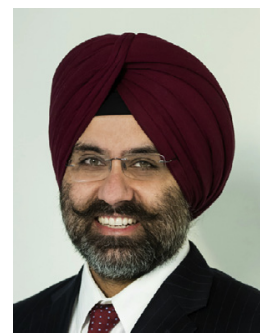

Dr Scott A. LeMaire (Houston, Tex). Did the surgeons use surgical adhesives or sealants during these repairs, and if so, is that another factor that you considered looking at in terms of whether it was a predictor of reoperation, either in a protective manner or a risk manner?

Dr Pan. What was the question? 
Dr Lemaire. Did you use surgical adhesives like glue or any of the sealants?

Dr Pan. Yes, glues were used, but I am not sure in what percent or how much. I'm not sure about that.

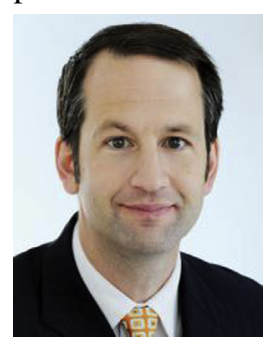

Mr Arminder S. Jassar (Boston, Mass). Thank you for an excellent presentation. When you are looking at late reoperations after surgery for type A aortic dissection, do you think it would be a much cleaner data set to look at just the DeBakey type I's rather than including the DeBakey type II's in the analysis as well, especially because you have shown us that the reoperation rate was higher for DeBakey type I's? I don't think many surgeons would perform an aggressive operation in the setting of a dissection that was just limited to the ascending aorta. The question really is what distal operation to do in the setting of an acute DeBakey type I to prevent late reoperations.
Dr Pan. Thank you for the question. Yes, I think this is rather short follow-up at this time when reoperations can be performed much later, so I think we need longer follow-up to see. Maybe in the future we can separate DeBakey I and II and look at them separately.

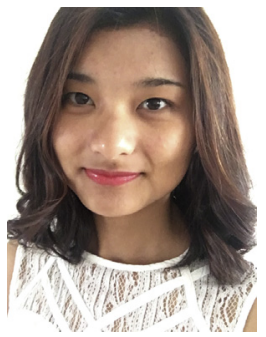

Dr Michael A. Borger (Leipzig, Germany). Just 1 other point I would like to mention is that an upcoming article shows a strong association between a new entry site at the distal suture line and future reoperation either in the arch or in the proximal thoracic aorta. The way we try to avoid this suture line entry site from occurring is to use just a little tiny bit of glue between the 2 dissected layers, hold them together for a minute, and then oversew the free edge of the distal aorta with 5-0 Prolene suture. This gives the surgeon a firm structure to sew to and eliminates the need for felt.

Dr Pan. Thank you for the comment. 